\title{
SYNTHESIS, GROWTH, STRUCTURAL, SPECTRAL, OPTICAL AND THERMAL PROPERTIES OF LITHIUM NITRATE DOPED
}

\section{THIOUREA CRYSTAL}

\section{P. SARITHA}

Department of Physics, Government College of Engineering, Thanjavur, Tamil Nadu, India

\begin{abstract}
In the current work is concerned with the analysis of Thiourea Lithium Nitrate Crystals have been grown and distinct characterization techniques are examined from the slow evaporation way of low temperature solution growth method at room temperature with double distilled water. The design and search of high effective nonlinear optical crystals for ultraviolet and visible regions are very vital for material and laser processing. In differently the very low concentration impurity does not have any influence on the arrangement. The FT-IR is efficiently utilized to identify the functional groups within the synthesis chemical and it's been discovered that extending of molecules in particular frequencies. The optical transparency and also the lower cutoff wavelength at 285 nm were identified in the UV-Vis NIR spectrum. The Kurtz and Perry powder strategy at second harmonic generation evaluation proves that the crystal is a promising candidate for great optical properties. Thermal analysis reveals that the grown crystals were thermal stability up to $210^{\circ} \mathrm{C}$.

KEYWORDS: Crystal Growth, Single and Powder XRD, FTIR, UV-Vis, NLO \& TG/DTA
\end{abstract}

Received: Jan 03, 2019; Accepted: Jan 23, 2019; Published: Apr 10, 2019; Paper Id.: IJPRJUN20193

\section{INTRODUCTION}

Crystal grew now-a-days find areas which range from microelectronics, medical devices, communicating systems, laser and defense resources up into the space satellites and age. Crystal expansion of notable role of drama in the age of immense technological superiority attributing to the viability in significant area of the humankind namely science, medicine, technology, technology and strategies Regions of defense and Several crystals are utilized in piezo-electric, acoustic-optic, picture refractive, photograph elastic, electro-optical programs and radiation, sensors, laser hosts, parametric amplifiers transducers, harmonic generators etc.,

Development of crystals from aqueous solution is just one of those early procedures of crystal growth. This system of crystal growth is very well known in creation of several technologically significant crystals. The development of crystals with low temperature alternative involves months and sometimes years.

Light is distracted or postponed however, it frequency is unchanged. Non-linear optics: Optics of extreme light we're worried about the effects that light itself causes since it spreads through the medium.

In the current work, another NLO substance of different percentage of lithium nitrate doped thiourea crystals have been grown from aqueous solution by dividing double distilled water utilizing slow evaporation technique at room temperature. The grown crystals of different proportion $(0.5: 2 \mathrm{M}, 1.0: 2 \mathrm{M}$ and $1.5: 2 \mathrm{M})$ were 
harvested. It is concerned with the investigation of the Thiourea Lithium Nitrate Crystals growth and different characterization techniques are analyzed.

\subsection{Materials}

All reagents are analytically high purity of Thiourea (Merck 99\%) and Lithium Nitrate (AR grade) were taken in different molar ratio $0.5: 2 \mathrm{M}, 1: 2 \mathrm{M}$ and 1.5:2M and dissolved in double distilled water.

Thiourea is a organosulfur compound Using the formula SC It's structurally like urea, except the oxygen molecule is replaced by a sulfur molecule and Thioureas are related to thioamides, eg. RC(S) NR2, where R is methyl, ethyl, etc., Thiourea is a reagent in organic synthesis.

Lithium nitrate is a natural compound together with the Formula LiNO3. It's the lithium salt of nitric oxide. It's made by Other group that I nitrates decompose otherwise, Forming the nitrite oxygen and salt. Due to its comparatively small size, the Lithium cation is quite polarizing, which simulates the creation of this oxide. Lithium nitrate can also be denser than water.

$$
4 \mathrm{LiNO}_{3}+2 \mathrm{Li}_{2} \mathrm{O}+4 \mathrm{NO}_{2}+\mathrm{O}_{2}
$$

\subsection{Solubility}

The solubility of lithium nitrate doped thiourea salts have been completed in a solvent of double distilled water in five fever $\left(30^{\circ} \mathrm{C}, 35^{\circ} \mathrm{C}, 40{ }^{\circ} \mathrm{C}, 45^{\circ} \mathrm{C}\right.$ and $\left.50{ }^{\circ} \mathrm{C}\right)$. The purified re-crystallized salts of TuLiNO3 were dissolved in double distilled water and all these alternatives are stored in an airtight container. Solubility analysis was completed with a magnetic stirrer and an electronic thermometer. The temperature was controlled with a voltage regulator connected to the magnetic stirrer (precision is $\pm 0.01^{\circ} \mathrm{C}$ ). At first, the answer was stored at room temperature and stirred consistently employing the magnetic stirrer for approximately three hours. It can be seen that the solubility $\mathrm{TuLiNO}_{3}$ mixed solutions increases significantly with increasing temperature.

\subsection{Synthesis}

Lithium nitrate doped thiourea salts were synthesized by dissolving lithium nitrate and thiourea in various molar ranges $(0.5: 2 \mathrm{M}, 1: 2 \mathrm{M}$ and $1.5: 2 \mathrm{M})$ by mixing in double distilled water at room temperature. The alternative of lithium ion was added into this solution of thiourea the mix had to be stirred vigorously to prevent precipitation of different stages. The TULiNO3 alternative was ready and kept at room temperature at a constant temperature bath having a precision of $\pm 0.01{ }^{\circ} \mathrm{C}$ with constant stirring to make sure continuing temperature immersion over the full quantity of this solution. The solution was stirred well for three hours constantly using magnetic stirrer, and was filtered by using Whattmann filter paper. These solutions are redistributed in three different beakers. These salts were purified by repeated recrystallization process by using double distilled water as solvent. The synthesized substances were purified by evaporation technique to obtain thiourea lithium nitrate mixed crystals of high quality, purification is an important steps. Hence, crystallizations were repeated for more than three times.

\section{PREPARATION OF CRYSTAL GROWTH}

The solutions were prepared by dissolving salts are lithium nitrate and thiourea in the different molar ratio of 0.5:2M, 1:2M and 1.5:2M in double distilled water at constant room temperature. The filtered solutions were distributed into different beakers $(100 \mathrm{ml})$. The solution was stirred well for about 6 hours using a magnetic stirrer constantly. 
The saturated solutions were filtered using Whattman filter paper. The filtered solutions were poured into different beaker and it is kept at a constant temperature bath maintained at room temperature in a dust free compartment for the slow evaporation process. The beaker was closed with a paper and the solution in the beakers was allowed to evaporate. After a few days small good optical transparent seed crystals are started growing in the beaker. After three weeks of growth colorless transparent crystals are obtained. Good shaped crystals were selected among the harvested crystal for the experimental studies.

Table 2.1: Optimized Growth Conditions of TuLiNO3 Crystals

\begin{tabular}{|l|c|l|c|}
\hline \multicolumn{1}{|c|}{ Crystals } & Growth Temperature & Period of Growth & Dimensions \\
\hline TuLiNO $_{3}$ 0.5:2M & $300 \mathrm{~K}$ & 25 to 30 days & $7 \times 7 \times 4 \mathrm{~mm}^{3}$ \\
\hline TuLiNO $_{3} 1.0: 2 \mathrm{M}$ & $300 \mathrm{~K}$ & 20 to 25 days & $17 \times 21 \times 8 \mathrm{~mm}^{3}$ \\
\hline TuLiNO $_{3} 1.5: 2 \mathrm{M}$ & $300 \mathrm{~K}$ & 20 to 25 days & $14 \times 8 \times 7 \mathrm{~mm}^{3}$ \\
\hline
\end{tabular}
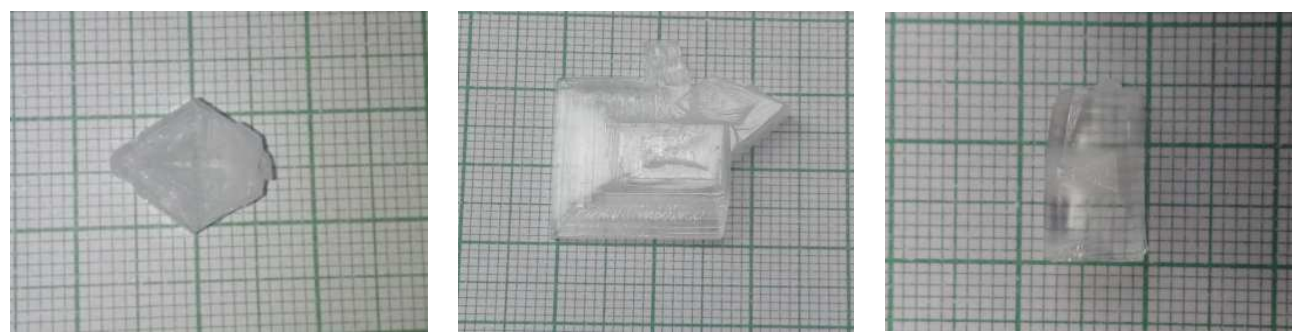

Figure 2.1: Photographs of Different Concentration of TuLiNO3 Crystals

\section{RESULTS AND DISCUSSIONS}

\subsection{Single Crystal XRD Analysis}

The Lithium nitrate doped thiourea crystal (1M: 2M) was subjected to Single X-ray diffraction studies using an ENRAF NONIUS CAD4 diffractometer with MoK $\alpha$ radiation $(\lambda=0.7173 \AA)$ to determine the unit cell dimensions. The structure have been solved by the direct method and refined by the full matrix least square technique using SHELXL programme. It was found that $\mathrm{TiLiNO}_{3}$ crystal belongs to orthorhombic system with a non-Centro symmetric space group $\mathrm{P} 2{ }_{1} 2_{1} 2_{1}$. These results are suggested that the induction of their legend in the $\mathrm{TuLiNO}_{3}$ crystals does not change the crystal system, though there is a small change in the lattice parameters.

Table 3.1: Unit Cell Parameters of TuLiNO3 Crystal

\begin{tabular}{|c|c|c|c|}
\hline Lattice Parameter & Thiourea & Lithium Nitrate & TuLiNO $_{\mathbf{3}}$ \\
\hline $\mathrm{a}(\AA)$ & 7.657 & 6.765 & 5.502 \\
\hline $\mathrm{b}(\AA)$ & 8.588 & 10.320 & 7.689 \\
\hline $\mathrm{c}(\AA)$ & 5.485 & 5.130 & 8.593 \\
\hline$\alpha^{\circ}$ & 90 & 90 & 90 \\
\hline$\beta^{\circ}$ & 90 & 90 & 90 \\
\hline$\gamma^{\circ}$ & 90 & 90 & 90 \\
\hline Crystal System & Orthorhombic & Orthorhombic & Orthorhombic \\
\hline Space group & Pnma $(62)$ & Cmcm $(63)$ & $\mathrm{P} 2_{1} 22_{1} 2_{1}$ \\
\hline Volume $\left(\AA^{3}\right)$ & 360 & 358.149 & 363.5 \\
\hline
\end{tabular}

\subsection{Powder XRD Analysis}

In the present work, Powder X-ray diffraction pattern of the grown $\mathrm{TuLiNO}_{3}$ crystal was recorded using EQUINOX-1000 model powder X-ray diffractometer with $\mathrm{CuK} \alpha(\lambda=1.540598 \AA)$ radiation for structural analysis of the crystal. The ideal Specimen is a statistically infinite amount of randomly oriented powder with crystallite size less than 10 
$\mu \mathrm{m}$, mounted in a manner in which there is no preferred crystallite orientation. Finely crushed powder of the crystal has been used for its analysis. The sample was scanned within the assortment of $10-80^{\circ}$ in a scanning speed of $1 \% \mathrm{~min}$. The intensity of the diffracted beam was listed as a part of $2 \theta$ along with the peaks have been clicked XRD pattern for the crystal is displayed at the Figure 3.1. The lattice parameters and cell volume values for the doped crystals are given in

Table 3.2.

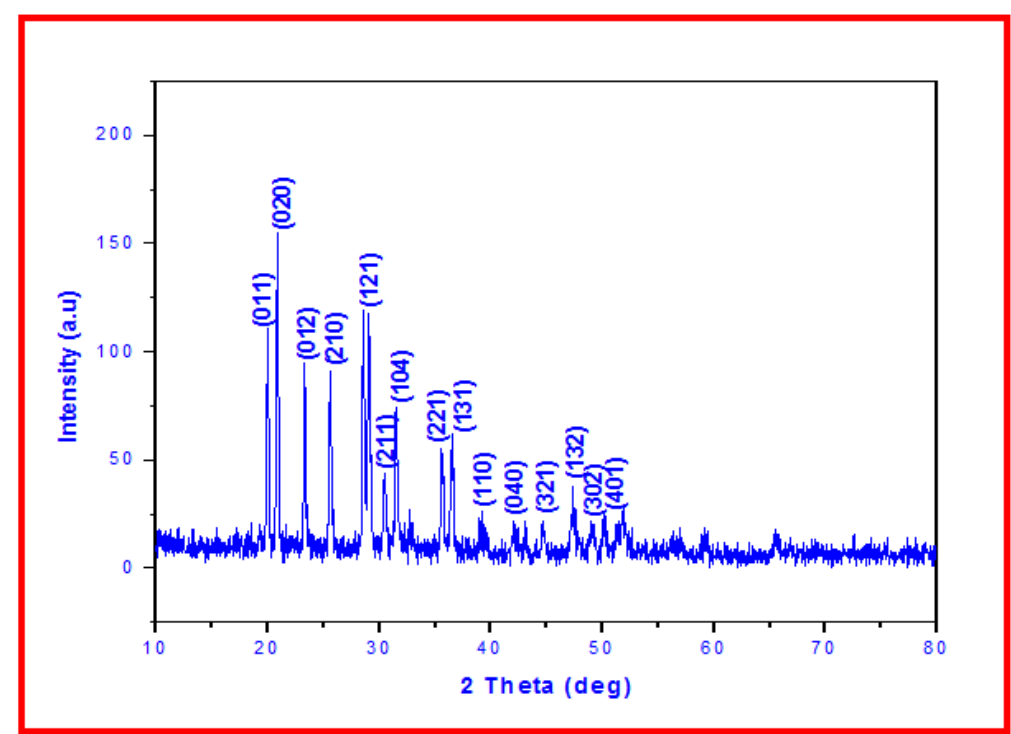

Figure 3.1: Powder XRD pattern of TuLiNO3 crystal (1M: 2M)

Table 3.2: Powder XRD Data of TuLiNO3 Crystal

\begin{tabular}{|c|c|c|c|c|c|}
\hline \multicolumn{2}{|c|}{ [ ${ }^{\circ} 2$ Theta] } & \multicolumn{2}{|c|}{ d-Spacing [̊] } & \multirow[b]{2}{*}{ (h k l) } & \multirow[b]{2}{*}{ References } \\
\hline $\begin{array}{c}\text { Observed } \\
\text { Value }\end{array}$ & $\begin{array}{l}\text { Standard } \\
\text { Value }\end{array}$ & $\begin{array}{c}\text { Observed } \\
\text { Value }\end{array}$ & $\begin{array}{l}\text { Standard } \\
\text { Value }\end{array}$ & & \\
\hline 19.951 & 19.185 & 4.621 & 4.622 & 011 & \multirow{15}{*}{$\begin{array}{c}\text { JCPDS } \\
\text { Card No. } \\
83-2252 \\
80-0203\end{array}$} \\
\hline 20.915 & 20.668 & 4.293 & 4.294 & 020 & \\
\hline 24.434 & 24.821 & 3.613 & 3.584 & 012 & \\
\hline 25.452 & 25.452 & 3.485 & 3.496 & 210 & \\
\hline 28.627 & 28.842 & 3.076 & 3.093 & 131 & \\
\hline 30.555 & 30.288 & 2.943 & 2.948 & 211 & \\
\hline 32.856 & 32.210 & 2.767 & 2.776 & 104 & \\
\hline 35.478 & 35.339 & 2.529 & 2.537 & 221 & \\
\hline 36.899 & 36.304 & 2.493 & 2.472 & 110 & \\
\hline 38.827 & 38.337 & 2.352 & 2.346 & 132 & \\
\hline 42.092 & 42.051 & 2.157 & 2.147 & 040 & \\
\hline 44.797 & 44.437 & 2.094 & 2.037 & 321 & \\
\hline 47.472 & 47.378 & 1.919 & 1.917 & 132 & \\
\hline 48.840 & 48.696 & 1.873 & 1.868 & 302 & \\
\hline 50.177 & 50.454 & 1.791 & 1.807 & 401 & \\
\hline
\end{tabular}

\subsection{Fourier Transform Infrared (FTIR) Analysis}

The FTIR analysis of lithium nitrate doped thiourea in different molar ratio $(0.5 \mathrm{M}: 2 \mathrm{M}, 1 \mathrm{M}: 2 \mathrm{M}$ and $1.5 \mathrm{M}: 2 \mathrm{M})$ of crystals were carried out in the region of 4000-400 $\mathrm{cm}^{-1}$ using SHIMADZU-8400 with a resolution of $4 \mathrm{~cm}^{-1}$. Figure 3.2 show the FT-IR spectrum of $\mathrm{TuLiNO}_{3}$ crystals. Other important functional groups are detailed in Table 3.3. 
Table 3.3: Vibrational Assignments of Lithium Nitrate Doped Thiourea Crystals

\begin{tabular}{|c|c|c|}
\hline Crystal & Wavenumber $\left(\mathbf{c m}^{-1}\right)$ & Assignments \\
\hline \multirow{5}{*}{ TuLiNO $_{4}$} & 3414,3400 and 3380 & Asymmetric- $\mathrm{H}_{2} \mathrm{O}(\mathrm{O}-\mathrm{H})$ Stretching \\
\cline { 2 - 3 } & 2360,2355 and 2350 & $\mathrm{NH}_{3}$ stretching \\
\cline { 2 - 3 } & 1636,1617 and 1607 & Symmetric $\mathrm{NO}_{3}$ stretching \\
\cline { 2 - 3 } & 1468,1458 and 1449 & $\mathrm{NH}_{2}$ bending \\
\cline { 2 - 3 } & 1100,1108 and 1120 & Asymmetric N-C-N stretching \\
\cline { 2 - 3 } & 892 & $\mathrm{C}-\mathrm{N}$ stretching \\
\cline { 2 - 3 } & 832 & $\mathrm{C}^{-\mathrm{H}}$ bending \\
\cline { 2 - 3 } & 825 & $\mathrm{NO}_{3}$ stretching \\
\cline { 2 - 3 } & 731 & Symmetric $\mathrm{C}=\mathrm{S}$ stretching \\
\cline { 2 - 3 } & 500 & $\mathrm{COO}-\mathrm{C}-\mathrm{N}$ stretching \\
\cline { 2 - 3 } & 466 & Symmetric N-C-N bending \\
\hline
\end{tabular}
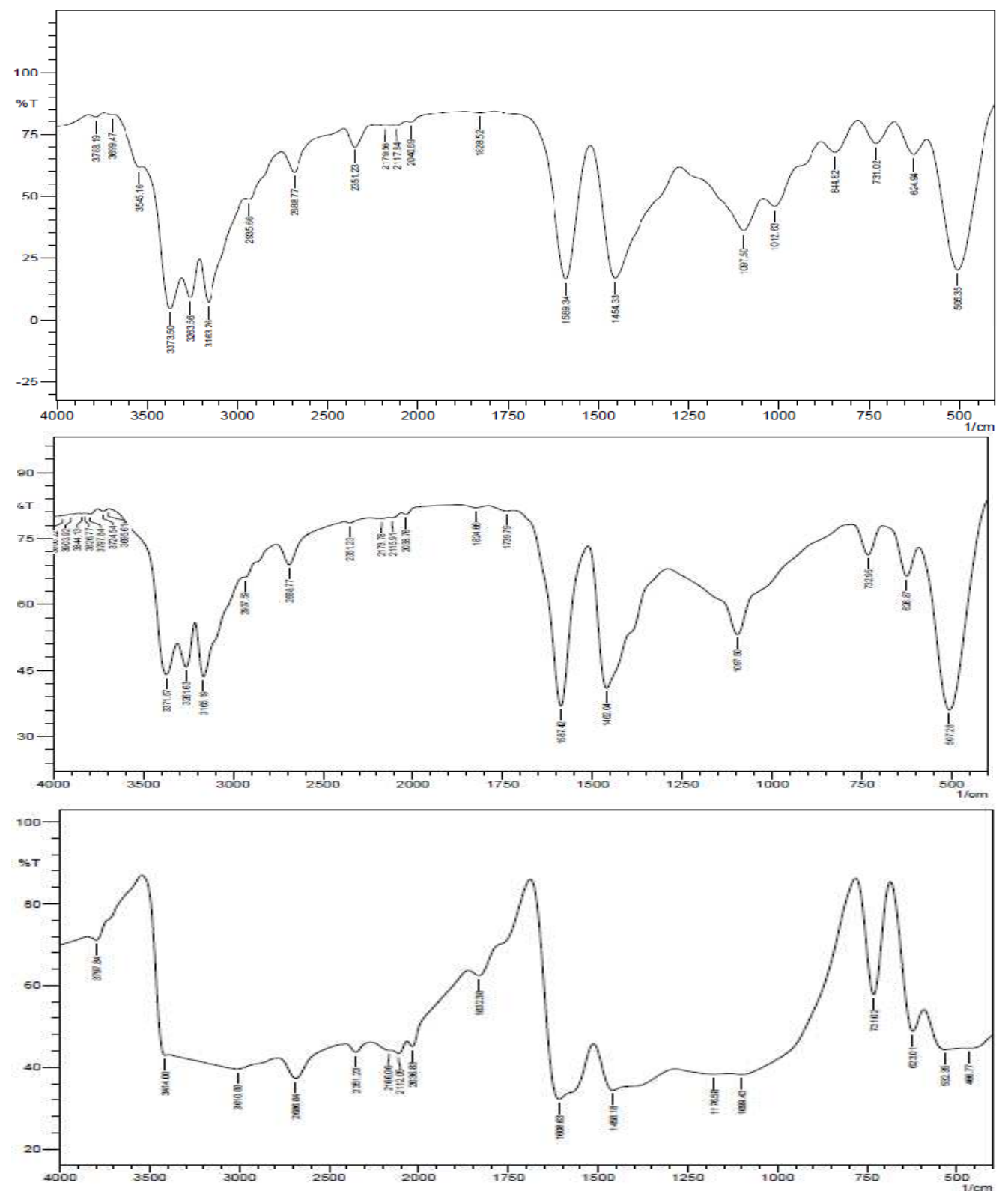

Figure 3.2: FT-IR Spectrum of TuLiNO3 Crystals for Different Molar Ratio (a, b and c) 


\subsection{UV-Vis- NIR Study Analysis}
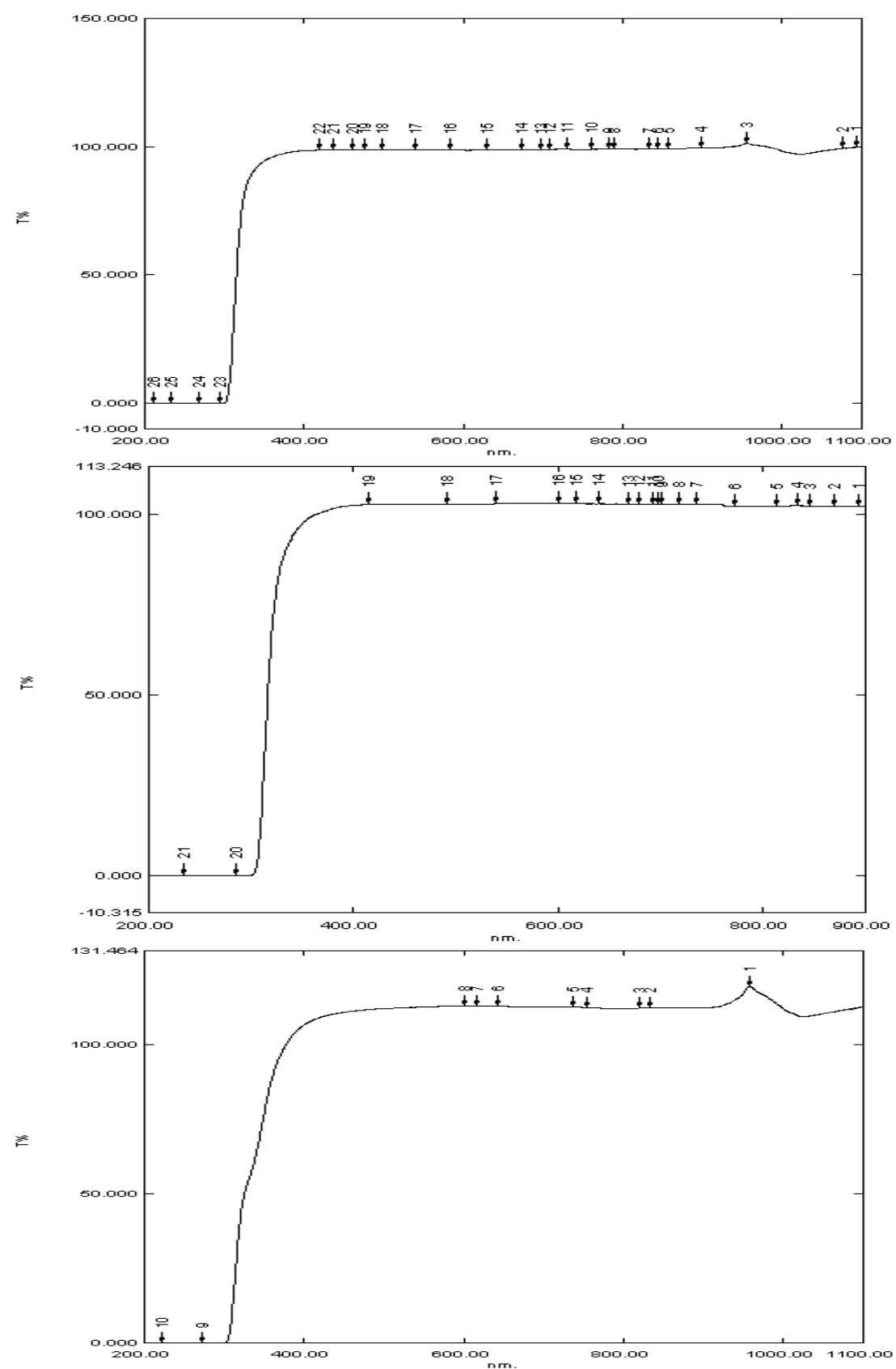

Figures 3.3: UV-Vis Spectrum of TuLiNO3 Crystals for Different Molar Ratio (a, b and c)

UV-Vis-NIR spectral study is a useful tool to determine the transparent for a material to be optically active. The optically transmission spectrum of lithium nitrate doped thiourea in different molar ratio $(0.5 \mathrm{M}: 2 \mathrm{M}, 1 \mathrm{M}: 2 \mathrm{M}$ and $1.5 \mathrm{M}: 2 \mathrm{M})$ of crystals were recorded in the range $200-1100 \mathrm{~nm}$ by shimadzu - UV1800 spectrophotometer at room temperature.

It covers a broad region near ultraviolet (200nm to $400 \mathrm{~nm})$, visible $(400 \mathrm{~nm}$ to $800 \mathrm{~nm})$ and far infrared $(800 \mathrm{~nm}$ to $1100 \mathrm{~nm})$. The observed plot of transmittance (\%) Vs wavelength (nm) is shown in Figure 3.3. At lower cutoff wavelength $285 \mathrm{~nm}$, a sharp fall of transmission to zero was observed, indicating a single transmission in the near UV region thiourea. From the value of fundamental absorption wavelength, the band gap energy of the material is calculated using the formula,

$$
\mathrm{Eg}=\mathrm{hc} / \lambda(\mathrm{eV}) ; \quad \mathrm{Eg}=4.36 \mathrm{eV}
$$




\subsection{Second Harmonic Generation Studies}

To be able to locate the SHG, the crystals have been ground with a version to the Kurtz and Perry method into powder (roughly $70 \mu \mathrm{m}$ ) and densely packed between 2 translucent microscope glass slides. After the samples are put on the glass slides, aQ - Switched style Nd:YAG Quanta beam series laser of $1064 \mathrm{~nm}$, creating an $8 \mathrm{~ns}$ pulse and functioning in $6 \mathrm{~mJ} /$ pulse and in a speed of $10 \mathrm{~Hz}$, is pumped in the appropriate angle and distance so as to see clearly the SHG from the green color area $(532 \mathrm{~nm})$, the anticipated emitted half wavelength indicate.

The second harmonic signals generated in the crystalline sample were confirmed from emission of green radiation by the sample. The SHG efficiency of the $\mathrm{TuLiNO}_{3}$ Crystal for different molar ratio (0.5:2M, 1.0:2 $\mathrm{M}$ and 1.5:2M) was evaluated by taking the microcrystalline powder of KDP as the reference material. The second harmonic signal for KDP is $8.8 \mathrm{~mJ}$. The powder SHG efficiency output was found to be 0.73 times greater with respect to KDP. The NLO conversion relative efficiency of thiourea lithium nitrate crystals was presented in Table 3.4.

Table 3.4: SHG Efficiency of the TuLiNO3 Crystal

\begin{tabular}{|c|c|c|c|}
\hline $\begin{array}{c}\text { No. of } \\
\text { Samples }\end{array}$ & $\begin{array}{l}\text { Samples, Code } \\
\text { Name }\end{array}$ & $\begin{array}{c}\text { NLO efficiency } \\
\text { Output Power }(\mathrm{mJ})\end{array}$ & $\begin{array}{c}\text { Relative } \\
\text { Efficiency }\end{array}$ \\
\hline & $\begin{array}{c}\text { KDP } \\
\text { (Reference Standard) }\end{array}$ & 8.8 & 1.00 \\
\hline 1. & $\mathrm{TuLiNO}_{3} \quad 0.5: 2 \mathrm{M}$ & 5.9 & 0.67 \\
\hline 2. & 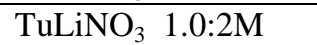 & 6.2 & 0.70 \\
\hline 3. & $\mathrm{TuLiNO}_{3} \quad 1.5: 2 \mathrm{M}$ & 6.4 & 0.73 \\
\hline
\end{tabular}

\subsection{Thermal Analysis}

Thermal analysis is a very essential method to study the thermal behaviour of materials and finds widespread applications in diverse industrial and research fields. The TG-DTA measurements were performed in nitrogen atmosphere at a heating rate of $20^{\circ} \mathrm{C} / \mathrm{min}$ for the temperature range of 30-1100 ${ }^{\circ} \mathrm{C}$ using STA-500 simultaneous thermal analyzer,

The lithium nitrate doped thiourea crystal $(0.5: 2 \mathrm{M}, 1.0: 2 \mathrm{M}$ and 1.5:2M) samples shows a thermal stability of the material $210{ }^{\circ} \mathrm{C}$ and there is no weight loss occurs. From TGA analysis curves, the maximum rates of degradation were at different temperatures and the second degradation step was indefinite. The onset points for the starting point of the $\mathrm{TuLiNO}_{3}$ crystals were at $222{ }^{\circ} \mathrm{C}, 215{ }^{\circ} \mathrm{C}$ and $210{ }^{\circ} \mathrm{C}$ respectively.

The DTA spectra of TuLiNO3 crystal Signify an endothermic transition round $200{ }^{\circ} \mathrm{C}$ and an exothermic one at roughly $250{ }^{\circ} \mathrm{C}$. This results reveal that the lithium ion samples reveal a significant endothermic transitions at $260{ }^{\circ} \mathrm{C}$. TuLiNO3 indicates another endothermic transition in over $600^{\circ} \mathrm{C}$. In this temperature range, the potential NLO software become promising, as a result of usage of laser powers, demonstrating a fantastic performance below $250{ }^{\circ} \mathrm{C}$. 

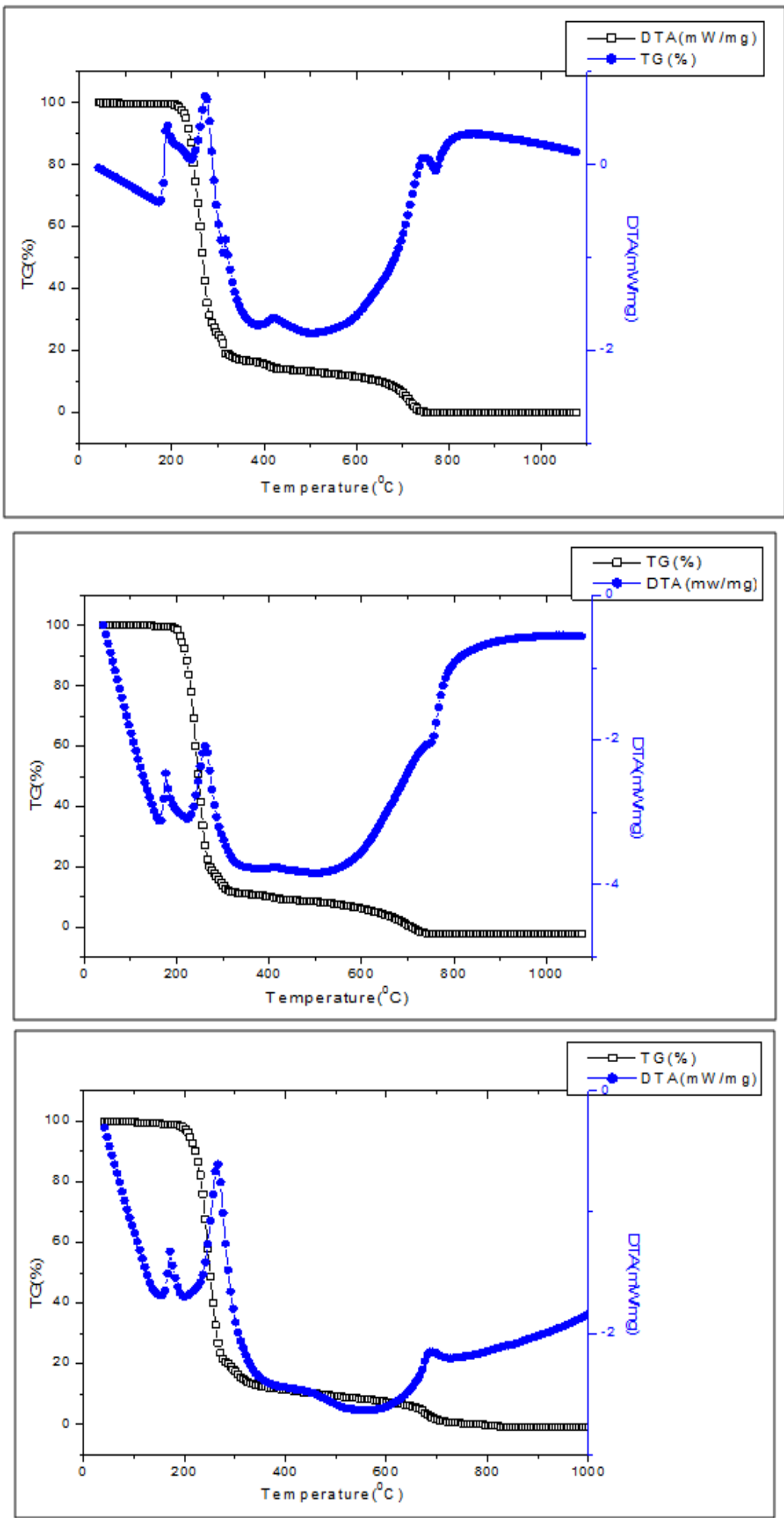

Figure 3.4: TG-DTA Curves of TuLiNO3 Crystals (0.5:2M, 1.0:2M and 1.5:2M)

\section{CONCLUSIONS}

The X-ray spectroscopic analysis of the doped specimen confirms the presence of lithium nitrate in the crystalline matrix of thiourea crystal. The lattice parameters were determined from the single crystal XRD and it has been found that $\mathrm{TuLiNO}_{3}$ belongs to the orthorhombic crystal system. The sharply well defined Bragg's peak confirms the crystalline 
nature of the grown $\mathrm{TuLiNO}_{3}$ crystal. It was confirmed by powder XRD pattern. The FT-IR study confirms presence of the functional groups in the samples. The thermal stability observed for the lithium nitrate doping of Thiourea crystals to be found as $210{ }^{\circ} \mathrm{C}$. The TuLiNO 3 crystal is melting point at $260{ }^{\circ} \mathrm{C}$. The optical transparency and the lower cutoff wavelength at $285 \mathrm{~nm}$ were identified from the UV-Vis NIR spectrum. The powder SHG efficiency output was found to be 0.73 times greater with respect to KDP. The Kurtz and Perry powder technique shows that the crystal is a promising candidate for good optical and opto-electronic applications.

\section{REFERENCES}

1. Ajitha Sweetly M and Chithambarathanu T, (2014). "Synthesis and Characterization of Pure and Lithium nitrate doped Sodium bromate Single Crystals", International Journal of Scientific \& Engineering Research, 5, 965-971.

2. Ambujam K, Rajarajan K, Selvakumar, S, Vetha I, Ginson P, Sagayaraj P, (2006). J. Cryst. Growth, 286, 440-444.

3. Arthi M, Sumithra Devi K. Thamizharasan, (2014).Structural, Microhardness, Photo-conductivity, and Dielectric Properties of Tris(thiourea) Cadmium Sulphate Single Crystals, Hindawi Publishing Corporation, Journal of Solid State Physics, 5, 5-8.

4. Begum S A, Hossain M and Podder J, (2009). "An investigation on the growth and characterization of thiourea single crystal grown from aqueous solutions", Journal of Bangladesh Academy of Sciences, 33, 63-70.

5. Boaz B M, Rajesh A L, Jesu S X, Das S J J, (2004). Cryst. Growth, 262, 531-535.

6. Saboo, S., \& Gupta, C. P. (2013). Design Of Photonic Crystal Fiber For Minimum Confinement Loss By Varying The Size Of Holes. International Journal of Electronics and Communication Engineering (IJECE), 2(2).

7. Dooslin Mary D, Mary Freeda M, and Gerardin Jayam, (2015). "Solution growth and Studies of undoped and lithium nitrate added glycine sodium nitrate single crystals", Journal of chemical and Pharmaceutical Research, 7, 242-246. 
